\title{
Enrique Foffani, Vallejo y el dinero. Formas de la subjetividad en la poesía. Lima, Cátedra Vallejo, Archivo Vallejo, 2019, 414 páginas ${ }^{1}$
}

\author{
Gustavo Lespada
}

Cita sugerida: Lespada, G. (2020). [Revisión del libro

Vallejo y el dinero. Formas de la subjetividad en la poesía por E. Foffani]. Orbis Tertius, 25(32), e183. https://doi.org/10.24215/18517811e183

Desde su inicio Vallejo y el dinero de Enrique Foffani nos lleva hacia un planteo que hunde sus raíces en el siglo XIX: el shock de los profundos y bruscos cambios que la época moderna provocó en la humanidad. Trauma que dejó impresa su huella en la literatura desde los simbolistas franceses hasta la Escuela de Frankfurt, pasando por todos los ismos del siglo XX. La introducción tiene un epígrafe tomado de una crónica de Vallejo de enero de 1927, en la que se menciona la inauguración en París del boulevard Haussmann y se consigna su costo total de mil doscientos millones de francos, la cita del peruano se complementa con otra de Walter Benjamin que alude a la figura del prefecto Haussmann (bajo Napoleón III), quien pasó a la historia no sólo como el reformador de la ciudad de París sino también como alguien que manipuló fondos del estado y favoreció la especulación financiera.

A partir de esta "entrada" y siguiendo las huellas de Benjamin, Foffani recala en "El hombre de la multitud" para desplegar, hilo a hilo, la trama del misterio y las sutiles señales del dinero en el relato de Edgar Allan Poe. Como sabemos, el cuento será retomado luego por el flaneur baudelaireano y —en una virtuosa trenza literaria - vuelto a leer por Benjamin, quien percibe ese estado de alerta que se apodera del transeúnte en la abigarrada ciudad. En ese cuento magistral ya están in nuce los elementos primordiales de la modernidad, sobre todo porque también se evidencia la relación que interesa: "la de la subjetividad y el dinero en la escena moderna”. Pero además, se plantea una primera disidencia respecto de la crítica vallejiana: 
Contra la doxa crítica que afirma que Vallejo se enfrenta a la modernidad en Europa, más concretamente en París, nuestra lectura sostiene lo contrario: que esta experiencia urbana de shock (...) fue vivida en Lima (...) e incorporada a su poesía en un libro: Trilce, publicado en 1922.

E incluso que ya había marcas de esa experiencia extrañada de la ciudad en su primer poemario, en aquellas impresiones urbanas recibidas a través de los relatos de su padre cuando fuera gobernador en su pueblo natal, Santiago de Chuco (p. 15).

Este primer planteo, a su vez, sienta las bases para otra relación constitutiva de la poesía vallejiana que se desarrolla más adelante en forma integral: la oposición comunidad serrana (andina, de la infancia y juventud) versus la metrópolis moderna (Bizancio: Lima, París). Y en esa tensión, dice Foffani, los rigores del capitalismo leídos en el cuerpo humano podría ser una de las claves de la poesía de Vallejo (p. 45). Clave de lectura, por cierto, muy coherente con "la imagen del poeta inmerso en la experiencia social y al mismo tiempo en la poesía pura” (p. 47). Esta síntesis acerca de la poesía de Vallejo viene a saldar, de alguna manera, el déficit analítico que dividiera las aguas de la crítica vallejiana puesto que uno de los aspectos más admirables de Vallejo es la convergencia de una experimentación radical, extrema sobre el lenguaje, con un incorruptible compromiso humano y social.

En el capítulo "La escena contemporánea del dinero", el análisis exhaustivo da cuenta no sólo de la presencia del dinero - o de su falta, que es una presencia más acuciante todavía - desde los orígenes de la poesía vallejiana, sino que también actualiza, recompone, el encuadre sincrónico de la época. Así, entre 1920 y 1921, mientras Vallejo ha publicado sus Heraldos... y se encuentra escribiendo su poemario Trilce en Perú, Walter Benjamin, en Europa, escribe un bosquejo ensayístico en el que propone entender al Capitalismo como religión, como "un culto que no da tregua ni posee misericordia en ese proceso de transformación", a través "de la imagen del parásito con fuertes resonancias en el mundo mercantilizado de la contemporaneidad” (p. 40). ¿Por qué reunir a Benjamin con Vallejo? Porque mientras el teórico europeo interpreta críticamente al régimen político y económico imperante, la producción del poeta se contrapone drásticamente con las leyes del capitalismo. Frente a ese sistema de explotación, de robo por medio de la plusvalía - recordemos que Trilce imagina el destino del hombre como "oro en desgracia", el codiciado metal que aleja al hombre del estado de gracia-, frente a su modo de "usurpación con efectos fantasmagóricos" respecto del producto del trabajo, la poesía restablece el don, esa dimensión del acto de donar o de dar más alineada con la lógica del potlach, es decir, con una acción que se ubica en las antípodas de las relaciones contractuales del mercado; y ese donar que incluye siempre al otro, al prójimo, constituye el núcleo sustancial de la poética vallejiana (p. 41).

Por todo esto es que Foffani entiende que para Vallejo la poesía es un Ersatz compensatorio, un resguardo de la adversidad, "un espacio contracapitalista" (p. 55). Por otra parte, aunque la pobreza - que en términos de la economía de mercado se traduce en falta de dinero - fue una constante dramática en su vida, Vallejo siempre defendió la autonomía del arte sin evadir el compromiso social: "supo poner al abrigo del capitalismo la dignidad del escritor” (p. 47). De allí el paralelismo autorreferencial con el poeta León Bloy (p. 56).

El estudio del entorno y la historia reciente del Perú proporcionan un tejido de referencias ideológicas indispensables para comprender la obra de Vallejo. La reconstrucción documentada no sólo restablece el afectivo y fructífero vínculo con Carlos Mariátegui sino que le permite al crítico encontrar el denominador común entre la concepción de la poesía de González Prada y la de César Vallejo en el compromiso con la injusticia social en el Perú, sobre todo respecto de los indígenas (p. 69). Aunque en este rasgo temático en común sus poéticas se diferencian: en tanto que el signo anarquista de González Prada se manifiesta dentro de una estética romántico-modernista, el incondicional compromiso con la pobreza y la iniquidad en Vallejo posee un fundamento cristiano y buscará expresarse con recursos de la renovación estética aunque, paradójicamente, Trilce no encuentre sitio en la vanguardia peruana, demasiado pendiente de la moda tecnológica del Futurismo. 
Partiendo de la fórmula paradojal que Noé Jitrik pensara tanto para el Facundo como para la poesía de Vallejo: “A pobreza del entorno, riqueza del producto" (1992, pp. 77-80), Foffani expone la transmutación del saqueo colonial de bienes materiales en bienes espirituales o simbólicos. A partir de la explotación y la pobreza generada por la depredación capitalista, el escritor responde produciendo una riqueza estética, un patrimonio cultural: "El poeta parece sacarle provecho a la carencia, una suerte de utopía contracapitalista" (p. 339).

El texto ahonda en los estudios de Georg Simmel sobre la cultura y la función capital que cobra el dinero en la sociedad moderna (p. 86), así como su ampliación sobre la teoría del valor de Marx que había puesto en evidencia el predominio del dinero como un proceso que invertía y alienaba las relaciones sociales de producción (p. 89). El análisis simmeliano orientado al examen de la economía monetaria, y centrado en el intercambio social más que en la producción, desemboca en el fenómeno del consumo cuyas ramificaciones y consecuencias afectan y atraviesan todas las esferas de la vida moderna incluida la subjetividad de las personas. El dinero se manifiesta como el paradigma del individualismo desvirtuando, pervirtiendo los valores humanos, como la ética y la solidaridad (p. 97).

La relación entre el dinero y la vida anímica se desarrolla principalmente en las grandes ciudades, sedes del tráfico monetario y centros de la indiferencia e insensibilidad psicológica y social. Simmel piensa las grandes ciudades como el reino del Capitalismo pero también como el lugar vacío de afectividad y, justamente, esa es la experiencia que vive César Vallejo como sujeto migrante primero en Lima y después en París, en duro contraste con su comunidad serrana (p. 362). Esta línea de análisis imprescindible será ampliada recurriendo a los aportes teóricos de Lukács, Frisby, Mauss, Kurnitzky, Berman y Agamben, entre otros, con la finalidad de aportar el espesor reflexivo y la dimensión conceptual del problema. ¿Por qué decimos "imprescindible"? Porque tenemos tan incorporado a nuestra cotidianeidad el dinero que sólo un sacudón teórico puede hacernos tomar conciencia del carácter siniestro de un "medio" (de pago) que pasó a ser un fin en sí mismo y que rige nuestras vidas.

En el capítulo 2, dedicado a Trilce, aparece enunciada una hipótesis fuerte: el proceso de escritura poética de Vallejo practicaría una crítica al capitalismo sin nombrarlo desde sus primeros poemas, aunque algunas composiciones se orienten hacia la sublimación. Esta acotación explicaría por qué la crítica, salvo excepciones, lo ha pasado por alto. El poema T. XXIII es un ejemplo paradigmático de esta confrontación — muy presente en toda la saga familiar desde Los heraldos...-, en el cual, además de las innovaciones formales, hay una nítida oposición entre "ese ayllu familiar que es un espacio de indudable transculturación" y el capitalismo representado en "el alquiler del mundo" (p. 112-119). A partir de los planteos sociológicos mencionados y el concepto benjaminiano de la muerte de la experiencia como signo de la modernidad, se pueden dimensionar los efectos discursivos de ese shock que el sujeto poético serrano experimenta en la gran ciudad, en este caso, Lima.

"Trilce es un libro de la memoria en múltiples sentidos" - destaca Foffani- (p. 121) con un proceso de enunciación muy complejo que a grandes rasgos obedece a la dinámica de oposición presentepasado, presencia-ausencia, abundancia-carencia, sierra-ciudad y niño-adulto, sobre todo en la saga familiar. Pensemos en cuánta carga emotiva aporta este procedimiento del atajo y sobre todo, en el caso de Vallejo, cómo aumenta la tensión sierra andina-metrópolis. En T XXIII el alimento se manifiesta bajo su doble referencia: a los valores cristianos (ricas hostias de tiempo) y a la significación socialista del mundo del trabajo: "de dual estiba" (p. 128). En la página siguiente concluye, sin ambages: "La visión de Vallejo (...) parece fusionar lo andino y lo cristiano, pero aunándolos en una crítica al presente cuyo blanco es el sistema económico capitalista" (p. 129). Veamos este cierre de capítulo: frente a esta realidad mercantilista y excluyente con su "lógica de alquilar el mundo", la respuesta de Vallejo es cósmica. Frente a este desalojo humano que impone el sistema capitalista la poesía puede pensarse como un sucedáneo compensatorio porque: “(...) aún frente a esta verdad constatable, la lengua poética es la expresión de ternura y de dulzura, de una intensidad emocional poco frecuente” (p. 135). 
El examen fino, meticuloso, advierte que los juegos de palabras vallejianos, las alteraciones o las asociaciones fonemáticas no son meros trucos vanguardistas. Foffani desarrolla, abre, vivisecciona la trama ideológica de esas operaciones asociativas que suelen decir mucho sin decirlo. Así, en el poema T LXIII se asocia el orín con el oro mediante el fonema or en común, ambos también remiten a la oralidad, a la cavidad oral del que habla y recuerda y, por esa vía, se conecta con el alimento, ya que la retrospección vallejiana siempre se vincula con la comida comunitaria, familiar. El texto despliega la constelación del poema que nos habla de un pasado histórico — capaz de vincular al Cuzco con la Alejandría de "oxidente" (con equis, para que aluda al óxido, a su deterioro) - pero también de un pasado individual, y entonces el oro de la infancia puede ser el "establo divinamente meado" y a la vez un poder que oxida civilizaciones (pp. 138, 139).

Por otro lado, si la subjetividad en la modernidad disgrega al sujeto cartesiano — Freud mediante- - y esta atomización desde Baudelaire (o Poe) aparece ligada a la vida urbana, en el caso de Vallejo se potencia puesto que el peso contrastivo de la cultura indígena, andina, se enfrenta trágicamente con la experiencia alienante de lo urbano. En cuanto a los recursos líricos del hermetismo - que aquí se interpretan como un resguardo de la poesía frente a "la estafa capitalista", como la llama Vallejo-, con agudeza se detecta el anticipo del trabajo trílcico en su poesía anterior hasta desembocar en el acto poético extremo, el de corroer los fundamentos de la estética en la que Vallejo había comenzado a escribir, el Modernismo (p. 160). Esta perspectiva disuelve la tajante frontera que cierta miopía crítica establece frente a Trilce y, llevando a cabo verdaderas operaciones de captura - para decirlo con palabras de Alain Badiou-, demuestra fehacientemente que esta matriz de enunciación tiene su momento inaugural en Los heraldos negros. Matriz basada en la oposición sierra-ciudad, caracterizada en detalle a partir de las modalidades específicas del acto de enunciar, cuando el sujeto toma la palabra para referirse al mundo y a sí mismo, teniendo en cuenta el lugar desde donde se profiere el discurso, ya que se trata de un locus que define posicionamientos sociales, éticos, ideológicos, étnicos, económicos, filosóficos y religiosos (p. 196).

En la nostalgia por la vida comunitaria de los Andes se encuentran articulados los dos segmentos de la Historia - nos dice Foffani- la historia privada y la historia colectiva: el espacio individual ("Canciones del hogar") y el espacio comunal ("Nostalgias imperiales"), la casa familiar y la cultura indígena, el ámbito doméstico y la civilización andina. Este núcleo de pertenencia (en el que se funde lo individual con lo colectivo) choca con su opuesto que lo rechaza y niega en sus valores: la orfandad y las carencias que le depara la ciudad moderna, a las que se alude en poemas como "Idilio muerto"; "El pan nuestro" o "La cena miserable", todos ellos rigurosamente analizados (pp. 195-218). Por todo esto, más allá de la mayor carga en la transgresión formal de Trilce, Vallejo exhibe una nítida continuidad en su poesía, no sólo respecto de la saga familiar y la oposición sierra-ciudad, sino también en el aprovechamiento de la experiencia estética implícitos en la estructura enunciativa del sujeto. Además, el concepto marxista de "la modernidad como contradicción, como paradoja - detecta Foffani-, el lenguaje poético vallejiano lo inscribe en su primer libro como un conflicto de la enunciación y lo define a su vez de manera sorprendentemente clara cuando presenta al sujeto combatido por dos / aguas encontradas que jamás han de istmarse" (p. 219).

Respecto de los análisis textuales de los poemas más herméticos de Trilce, resulta iluminador el tratamiento pormenorizado que, lejos de interpretar de manera hermenéutica "descifrando" un sentido único, sigue los lineamientos barthesianos (de Critica y verdad) de continuar y expandir las figuraciones de la obra. En el tratamiento de Foffani el poema se abre en múltiples resonancias y direcciones pero a la vez, como en una sinfonía, se percibe una partitura integradora, o mejor, un guión general, una dimensión alusiva generada por las propias palabras, los fonemas, los cortes de los versos, los tiempos verbales, la homofonía o las transgresiones gramaticales. Ejemplo virtuoso es el análisis del poema T XLVIII: que comienza con "Tengo ahora 70 soles peruanos" (pp. 228-236).

En los libros de edición póstuma, correspondientes a la etapa europea (1923-1937), vuelve a prevalecer la lengua materna, que la experimentación trílcica había hecho estallar, y se acentúa el carácter crítico respecto de la economía capitalista "que opera por confiscación y enajenación", dice Foffani, y señala algo que no 
siempre es tenido en cuenta: que aún cuando Vallejo estaba en Europa sumergido en la extrema pobreza, físicamente fuera de su país y de su cultura, su poesía nunca dejó de estar adentro de los valores comunitarios andinos (p. 250).

Aunque adhiere a la propuesta de Gutiérrez Girardot de leer en Vallejo al "marxismo en clave cristiana” y la idea de que en su poesía se funde el "camarada" revolucionario con el "prójimo" cristiano, Foffani da un paso más mediante una pregunta retórica: "¿Se funde uno en otro o el poema de Vallejo se funda en una experiencia que traspasa las ortodoxias y los catecismos?" (p. 285). Al reemplazar el verbo "fundir" por "fundar" ubica la formación y conciencia vallejianas en su verdadero origen y fundamento: la sierra andina, la cultura originaria, aquellas comunidades que la sociología caracterizó como "comunismo primitivo" porque en su organización prevalecía el bien común por sobre el interés individual.

El epistolario (Capítulo seis) si bien funciona como complemento de la figura del poeta también proporciona un marco histórico e ilumina muchos de los motivos y ejes de su producción. En las cartas se lee la cara más cruel de la necesidad, pero siempre críticamente, es decir, atendiendo no sólo a la semántica sino también a los aspectos formales del enunciado. Los constantes pedidos de dinero con la incierta promesa de devolución, el suplicio de la actitud mendicante apenas mitigada por el afecto (se trata de correspondencia con familiares o amigos) encuentran, sin embargo — nos dice Foffani-, un elemento que rescata de alguna manera al indigente: los recursos lingüísticos, como la ironía, el quiasmo o la paradoja, que le permiten desdramatizar su situación y recuperar, aunque sea parcialmente, la dignidad en riesgo: el capital retórico cubriendo la falta de capital pecuniario (pp. 354-360). Otra manifestación de la paradoja.

Pero la paradoja mayor está hacia el final del libro - o en la tapa-, en las reproducciones de las monedas y billetes peruanos con la cara de Vallejo (p. 394). "En la historia de la poesía latinoamericana no hay mayor ironía que esta: que aparezca la efigie de Vallejo en el papel moneda" — reflexiona Foffani-, justo él, que sufrió su escasez toda su vida, que fue su "oro en desgracia" (aquello que arrebata al hombre su gracia, su vínculo con lo sagrado), justo él que nunca respondió al fetiche del dinero "como el hombre moderno, cuya transacción no es sólo económica sino también sustitutiva" (p. 392). Justo él, allí, con la cifra numérica de un valor de cambio impresa al costado de su clásica imagen pensativa. ¿Qué diría Vallejo si se viera en el billete o la moneda? Probablemente esbozara una triste sonrisa y luego tal vez hiciera un comentario sobre la rapacidad del "execrable sistema" que tiende a apropiarse de todo, aún de aquello que lo confronta trastocando su signo, como la figura en lo alto del ábside del que crucificaron por pregonar la igualdad entre los hombres.

Vallejo y el dinero es un libro político, lúcido y valiente, cuyas reflexiones teóricas sacuden la modorra de la crítica literaria, porque no sólo se atreve a sostener la vigencia de los planteos sociológicos de Simmel (como la teoría de la alienación cultural además de su Filosofía del dinero) sino también a retomar y actualizar la mejor lección del marxismo acerca del sistema capitalista que, en su etapa corporativa actual, ha logrado imponer relaciones consumistas, fútiles y volubles con la finalidad de borrar la utopía del horizonte.

En medio de estos tiempos elusivos, de subjetividades travestidas y posiciones eclécticas e inestables, tiempos que favorecen al individualista y al pusilánime, "tiempos líquidos" — como dijera Zygmunt Bauman —, en medio de este páramo ético de la pos-verdad alentada por los mercenarios medios masivos — mejor dicho, por los empresarios de la in-comunicación-, aparece un libro que reedita los valores de la integridad y la consecuencia, aparece el trabajo de un intelectual con mayúsculas (un "obrero intelectual”, dijera Vallejo), un libro que nos recuerda la función que Theodor Adorno le atribuye al artista, al escritor: como lugarteniente del sujeto social y total. Un libro que defiende la autonomía de la literatura pero sin descuidar su compromiso histórico, político y social.

\section{REFERENCIAS}

Jitrik, N. (1992). Otra vez pobreza y riqueza. En La selva luminosa. Ensayos críticos 1987-1991 (pp. 77-80). Buenos Aires, Argentina: Facultad de Filosofía y Letras. 
Orbis Tertius, vol. XXV, n 32, e183, noviembre 2020-abril 2021. ISSN 1851-7811

\section{Notas}

1 Se publica la presentación del libro llevada a cabo en mayo de 2019 en Buenos Aires. 